\title{
Transition to work roles among youth in Bihar
}

International Institute for Population Sciences (IIPS)

Population Council

Follow this and additional works at: https://knowledgecommons.popcouncil.org/departments_sbsr-pgy

Part of the Demography, Population, and Ecology Commons, Family, Life Course, and Society Commons, International Public Health Commons, and the Medicine and Health Commons How does access to this work benefit you? Let us know!

\section{Recommended Citation}

International Institute for Population Sciences (IIPS) and Population Council. 2009. "Transition to work roles among youth in Bihar," Youth in India: Situation and Needs Policy Brief no. 17. Mumbai: IIPS.

This Brief is brought to you for free and open access by the Population Council. 


\section{Transition to work roles among youth in Bihar}

\begin{abstract}
"Achieving full and productive employment and decent work for all, including women and young people" is one of the targets articulated under the Millennium Development Goals and ratified by countries worldwide, including India. ${ }^{a}$ Also, reflecting India's commitment to meeting the employment needs of its citizens, new policy and programmatic initiatives have been launched in the country in recent years. For example, the Draft National Employment Policy aims to achieve "remunerative and decent employment for all women and men in the labour force"; , and the recently approved National Policy on Skill Development (2009) aims to empower individuals, especially youth and women, through improved skills, knowledge and qualifications to gain access to employment in an increasingly competitive global market. ${ }^{c}$ It is important, in this context, to take stock of the extent to which youth are equipped to make a successful transition to work roles and the extent to which they are indeed making that transition; this policy brief aims to do so for the state of Bihar. Specifically, are youth in the state transitioning into work roles at appropriate ages and with adequate skills? Are opportunities available that enable youth to overcome skill mismatches through vocational skills training? Are youth succeeding in finding productive employment and becoming integrated into the labour market?
\end{abstract}

Looking at the current employment situation of youth in Bihar, this policy brief argues that significant investment in terms of appropriate policies and programmes are required to improve the employability of youth in the state and thereby enable them to find full and productive employment.

\section{The study}

Data are drawn from the Youth in India:

Situation and Needs study, a sub-nationally representative study undertaken for the first time in India of key transitions experienced by young people in six states of India, including Bihar. The study included a representative survey of youth in both rural and urban settings. Respondents included unmarried women and men and married women aged 15-24 and, in view of the paucity of married men in these ages, married men aged 15-29.

In Bihar, the survey was conducted in 2007. A total of 8,136 married and unmarried young men and women were interviewed in the survey. These included 1,115 married young men, 1,492 unmarried young men, 2,341 married young women and 3,188 unmarried young women. This brief is based on data obtained from 1,942 young men and 5,529 young women aged 15-24.

The majority of youth were poorly equipped for employment

Findings from the Youth Study indicate that the majority of youth in the state were poorly equipped for employment for which there is a market demand. Most youth were neither adequately educated nor equipped with vocational skills.

\section{Few had completed secondary education} Just one in three young men (30\%) and one in eight young women (13\%) had completed secondary education, increasingly a prerequisite to participate in the labour market in the context of globalisation. ${ }^{\text {de }}$ Indeed, as many as one in six young men (16\%) and half of young women $(51 \%)$ had never been to school at all in the state.

\section{Few had acquired vocational skills}

A number of vocational training programmes are available to youth through government, nongovernment and private organisations. However, findings indicate that just $14 \%$ of young men and $10 \%$ of young women had ever attended a vocational training programme.

\footnotetext{
${ }^{a}$ United Nations Development Programme (UNDP). 2000. Millennium Development Goals. United Nations website. Accessed 8 January 2008 at <http://www.un.org/millenniumgoals/goals.html $>$.

${ }^{\mathrm{b}}$ Ministry of Labour and Employment. 2008. National Employment Policy. Accessed 15 October, 2009 at <www.labour. nic.in>.

c Planning Commission 2009. Coordinated Action on Skill Development. Accessed on 15 October, 2009 at <http:// planningcommission.gov.in/reports/ genrep/rep_csa.htm>.

d United Nations. 2007. Goals and targets for monitoring the progress of youth in the global economy: Report of the Secretary.

e National Research Council and Institute of Medicine. 2005. Growing up Global: The Changing Transitions to Adulthood in Developing Countries, Washington, D.C.: The National Academies Press.
} 
Percentage of youth who had ever attended a vocational training programme and who were interested in participating in such programmes

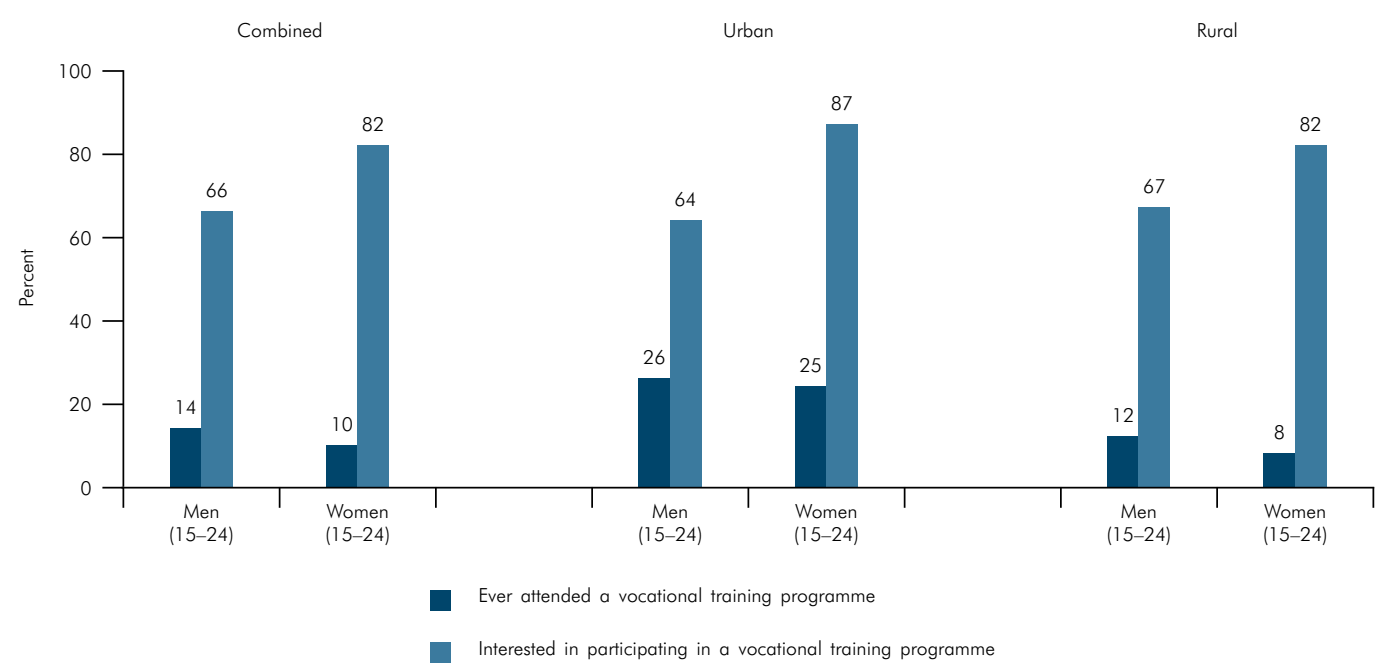

Moreover, findings show that the kind of training received varied by the sex of the respondent. Most young women who had received vocational training had typically acquired traditional skills. For example, over four in five $(82 \%)$ reported training in tailoring and one in three in handicrafts, painting or embroidery (31\%), compared to just $6 \%$ who reported training in computer skills. Young men were far less likely to report training in traditional skills (just 9\% and 15\% reported training in tailoring and crafts, for example). Indeed, among young men, leading training programmes reported included computer skills (23\%), auto mechanics or electrical work $(20 \%)$, driving (11\%) and English language, typing or shorthand (11\%).

Findings also show that large proportions of youth- $66 \%$ of young men and $82 \%$ of young women-were interested in acquiring vocational skills. While young men's preferences were focused on computer training, auto mechanics or electrical work, and driving, the majority of young women continued to opt for relatively traditional vocational skills, indicating a considerable disconnect between young women's preferences and market needs.

Transition to work roles was not easy or successful for many

Work profiles suggest that the majority of young men $(64 \%$ of the unmarried and $97 \%$ of the married) and a substantial proportion of young women (36\% and $38 \%$, respectively) had been engaged in paid or unpaid work at some point in the 12 months preceding the survey. Findings, however, highlight that the transition to work roles is fraught with challenges.

Sizeable numbers transitioned to work roles at young ages

Despite the global recognition that entry into the labour market at young ages competes with young people's schooling opportunities and experiences directly or indirectly, and compromises their productive potential and health, ${ }^{f}$ and despite significant policy and programme attention to the prevention of early entry into the labour market in India, ${ }^{\text {g findings }}$ indicate that sizeable proportions of youth had transitioned to work roles at young ages. Indeed, over one in three young men and women (35-37\%) reported that they had initiated either paid or unpaid work as children or young adolescents, that is, before age 15 . Rural youth were more likely than their urban counterparts to so report.

Percentage of youth who had initiated work in childhood or early adolescence (before age 15)

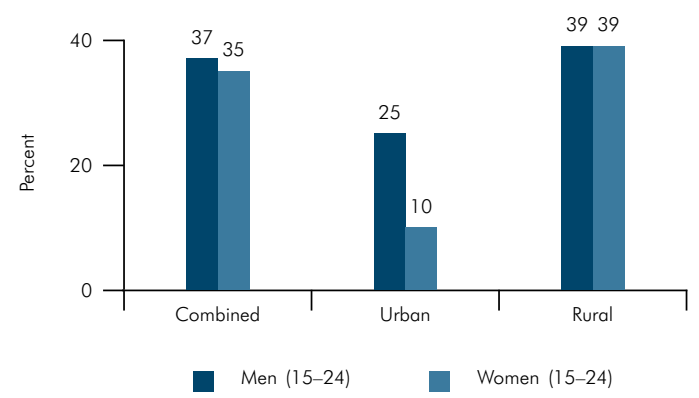

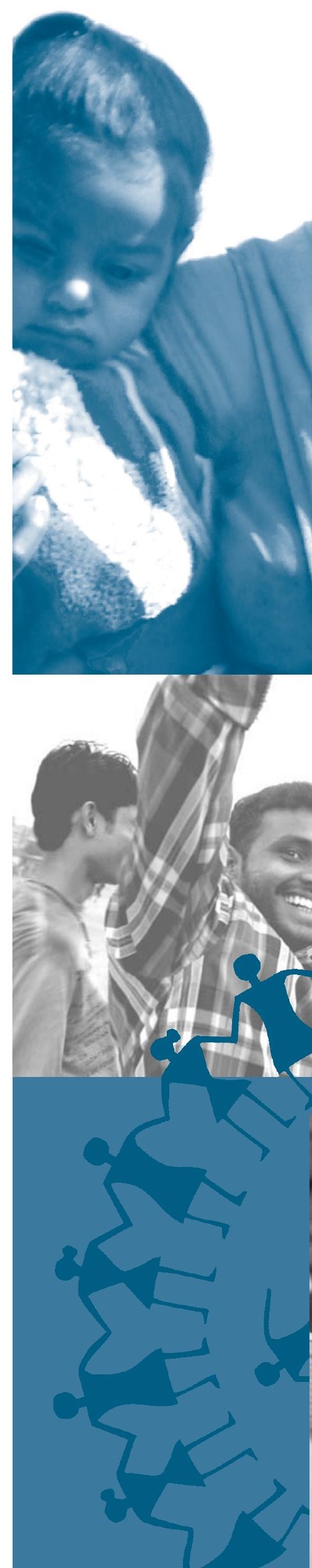

\footnotetext{
${ }^{\mathrm{f}}$ National Research Council and Institute of Medicine. 2005. Ibid.

g Ministry of Labour and Employment. 1986. The Child Labour (Prohibition and Regulation) Act 1986, New Delhi: Government of India.
} 
Many could not find full time employment

Findings indicate that among those who had engaged in paid work in the 12 months preceding the survey, many could not find full time employment, and young women were particularly disadvantaged in doing so; one-third of young men $(35 \%)$ and over half of young women (54\%) had worked for less than six months. Rural youth were more disadvantaged than urban youth in finding full time employment; $37 \%$ of rural young men compared to $23 \%$ of their urban counterparts, and $54 \%$ of rural young women compared to $48 \%$ of their urban counterparts had worked for less than six months.

Youth were largely engaged in agricultural and unskilled non-agricultural activities

The occupational profile of those engaged in remunerated work in the 12 months preceding the survey indicates that youth were largely engaged in agricultural and unskilled nonagricultural activities. Among working young men, 32\% reported unskilled non-agricultural labour. In contrast, skilled manual labour was reported by $24 \%$. Among working young women, over four-fifths $(83 \%)$ were engaged in agricultural labour. Just $2-7 \%$ of both young men and women were employed in administrative, executive, managerial or clerical occupations.
Considerable proportions of young people were unemployed

One-fifth of young men (22\%) and one-third of young women $(36 \%)$ reported unemployment. ${ }^{1}$ While unemployment rates were similar among both urban and rural young men, the rate among urban young women was considerably higher than that observed among their rural counterparts. While unmarried young men were three times as likely as married young men to report unemployment, among young women, the married were about as likely as the unmarried to report unemployment.

Notably, better educated youth were more likely to report unemployment than other youth, possibly because of the disconnect between youth skills and market needs. Among young men, for example, unemployment rate increased from $11 \%$ among those with no formal education to $47 \%$ among those who had completed Class 12. Among young women, the rate increased from $15 \%$ among those with no formal education to $77 \%$ among those who had completed 8-11 years of schooling and 68\% among those who had completed Class 12. These findings suggest that the paucity of opportunities limits the ability of even better qualified youth to obtain employment.

Unemployment rate among youth, according to selected characteristics

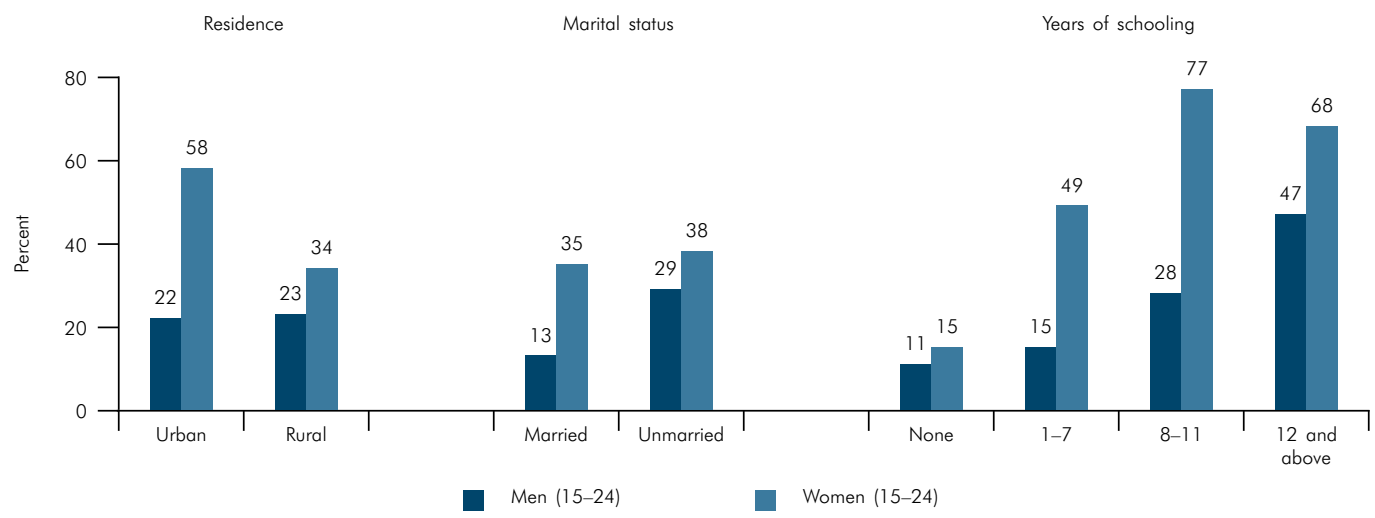

Economic activity and schooling status among youth

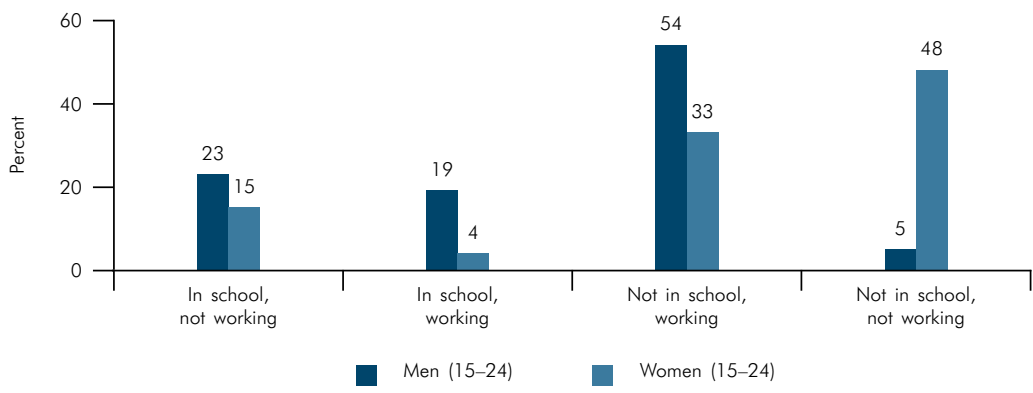

${ }^{1}$ To measure unemployment rates among respondents, the Youth Study assessed (a) whether youth had worked in the 12 months preceding the interview and if so, the number of months worked; and (b) whether youth were seeking work and if so, the number of months during which they had been searching for work. 
Many young women were neither in school nor working

Findings suggest that large proportions of young men and women were either in school or working at the time of the interview and a few were both working and studying. However, findings also show that the labour potential of young women was considerably under-utilised. For example, almost half of young women $(48 \%)$ were neither in school nor working, compared to just $5 \%$ of young men.

\section{Programme recommendations}

Findings indicate that several challenges remain in absorbing an increasingly youthful labour force and thereby harnessing the state's demographic dividend. A number of policies and programmes are needed to overcome these challenges.

\section{Increase investment in education}

Enhancing employability of youth would depend to a considerable extent on improvements in young people's educational attainment. Multiple activities are needed to achieve improvement in educational attainment. Efforts must be made, for example, to address the economic pressures that may discourage parents from enrolling or retaining their children in school in favour of work. Conditional grants and targeted subsidies that encourage schooling, and particularly school completion among disadvantaged groups also need to be considered. At the same time, activities are needed that are directed at parents that promote positive attitudes towards education and school completion, raise parents' aspirations for the education of their children and encourage greater parental involvement in their children's education.

Activities must also address school-level barriers, notably, poor infrastructure and quality of education. There is a need to incorporate livelihood skills building models within the school setting and provide opportunities for those in school to gain market-driven job skills that will expand the aspirations of youth regarding their education and careers. Moreover, investments in improving the quality of the schooling experience are needed that focus on providing better training of teachers and ensuring greater accountability among teachers.

Large numbers of youth have been left behind. There is a need to offer these youth a second chance at education, by way of evening schools and linking them with open schools.

\section{Enable youth to acquire vocational skills}

Findings have suggested that while programmes do exist, gaining access to these programmes is a significant obstacle for both young men and women; among those who obtained training, moreover, young women were particularly unlikely to obtain training in marketable skills. Formal mechanisms must be developed, therefore, that enable youth to access available training opportunities. At the same time, opportunities must be provided to youth that enable them to acquire skills for which there is an established demand, and that link eligible youth to market opportunities. These efforts need to promote self-employment and entrepreneurship through various livelihood schemes, for example, providing soft loans to youth to enable them to set up their own business enterprises.

\section{Ensure that existing programmes aimed at job creation reach youth}

While several programmes aimed at job creation are currently underway, the findings that considerable proportions of youth were unemployed at the time of interview and among those who were engaged in work for remuneration, many were not able to find full time employment suggest that these programmes fail to reach youth. Clearly, efforts are needed to ensure that existing programmes aimed at job creations do indeed reach youth. These programmes need to specially target young women.

Suggested citation: International Institute for Population Sciences (IIPS) and Population Council. 2009. Transition to work roles among youth in Bihar, Youth in India: Situation and Needs 2006-2007, Policy Brief No. 17. Mumbai: IIPS

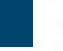

